\title{
Physical and energetic approach to providing solid wastes handling system with environmental safety
}

\author{
Oksana Paramonova*1, Vadim Bespalov ${ }^{1}$, Oksana Gurova ${ }^{1}$, and Natalya Krivtsova $^{1}$ \\ ${ }^{1}$ Don State Technical University, pl. Gagarina, 1, Rostov-on-Don, 344010, Russia
}

\begin{abstract}
Implementation features of the principal directions of municipal solid wastes handling system activity (territorial, climatic, economical and others) have stipulated the development of different concepts regarding to urban territories wastes handling, the most known of which are: Complex Waste Management, European Waste Management system (German dual system); «Zero Waste» concept. Each of the above mentioned concepts have got both advantages and disadvantages from ecological, economical, social, technological and organizational and legal points of view. From a perspective of the urban infrastructure environmental safety, an ecological aspect is the most interesting. That is why a new approach is being studied based on the principal points of the Theory of disperse systems sustainability which is called Physical and Energetic Description Concept of the Processes of Environmental Pollution and Restriction of Environmental Pollution with Municipal Solid Wastes. On the basis of the analysis of the municipal solid wastes handling concepts applied in the world and using the principal points of the theory of dispersed system sustainability, the results of the initial stage of the research regarding to studying and classifying municipal solid wastes properties parameters, their energetic parameters and sustainability have been represented by the authors. Herewith, the municipal solid wastes sustainability is considered as a resulting criterion characterizing municipal solid wastes behavior in the environment and allowing to control their behavior with the purpose of sustainability restriction and as a result decreasing the environmental pollution.
\end{abstract}

\section{Introduction}

Within a modern city a social infrastructure acting as a multisectoral complex for improving of community well being and life quality can be emphasized. Enterprises related to a housing and utility sector, trade and food services, household services, environment protection, life safety and others refer to a city-forming sphere that is the principal for the city sustenance.

The rational balance of forms and methods of direct and indirect management allows to

\footnotetext{
*Corresponding author: paramonova oh@mail.ru
} 
realize the main purpose of the city development-to create the environment of high quality as a combination of both people's living conditions and functioning of urban economic subjects. This purpose can be achieved through an integrated development of municipal infrastructure i.e. the systems of city sustainment and activity.

Urban economy is a complicated, dynamically developing complex of various, closely connected branches having a common aim - meeting vital important people's requirements as well as different organizations and enterprises located on the urban territory. One of the municipal subdivisions is a housing and utility sector that is responsible for collection, transport and utilization of Municipal Solid Wastes (MSW).

Such enterprises perform cleaning of grounds, provide waste collection and removal (containers, waste chutes, pneumatic transport); work out schemes of waste collection; inform legal and private persons, self-employed entrepreneurs about waste collection and transport; carry out the burial of wastes on special sites. However, the process of waste production and accumulation is dynamical i.e. it changes over time. And the process of wastes transport is more dependent on different factors and the management of this process demands immediate correction of previous decisions or even their revocation. The reasons of such changes can be stochastic, for example road traffic congestion, vehicles breakage, road repair and so on. Thus, enterprises themselves (to be exact equipment and transport used by them) functioning with the purpose of providing urban territories with environmental safety when MSW handling turns out to be the sources of the environmental pollution.

Functioning of enterprises, providing urban territories with sanitary cleanness is exercised according to a definite system of wastes handling.

Works of V.I. Bespalova [1-3], E.E. Borovskoy [4], Ya.I. Viersman [5], V.M.Garin [6], V.A. Grachev [7], A.S. Grinin [8], V.I. Smetanin [9], L.Ya Shubov [10,11] and others are dedicated to examination of the problem of wastes handling. Development of various programs, concepts and systems of wastes handling with consideration to influence of natural and climatic, physical and geographic peculiarities and resource and economic importance of urban territories has also been done by O.M.Cherp, V.N. Vinichenko [12], Robin Murray [13], Forbes R. McDougall, Peter R. White [14] and others.

Therefore, various natural and climatic, physical and geographic peculiarities and resource and economic importance of urban territories have stipulated the development and application of different wastes handling programs and systems which differ from each other by more detailed study of a certain aspect of activity (either technological, economical or ecological and economical) but not by its comprehensive study (taking into consideration organizational and legal, social and above mentioned aspects) that stresses the importance of the given problem researches connected with scientific reasoning of principles and developing of the methodology of MSW handling system on the basis of study of their properties and behavior in the environment at each stage of their life cycle with the purpose of providing urban areas with environmental safety.

\section{Materials and Methods}

The importance of the MSW handling problem is covered in mass media and no country in the world is in doubt about that. But the peculiarities of realization of the principal directions of MSW handling system (territorial, climatic, economical and others) have stipulated the emergence of different MSW handling concepts $[12,13,15,16]$, the most known of which are presented in table 1. 
Table 1. Main Results of Known MSW Handling Concepts Analysis.

\begin{tabular}{|c|c|c|c|c|}
\hline $\begin{array}{l}\text { Characte- } \\
\text { ristics }\end{array}$ & $\begin{array}{l}\text { Complex wastes } \\
\text { management [12] }\end{array}$ & $\begin{array}{c}\text { European } \\
\text { waste management } \\
\text { system (dual system) } \\
{[15]}\end{array}$ & $\begin{array}{l}\text { «Zero Waste» } \\
\text { concept [13] }\end{array}$ & $\begin{array}{c}\text { Physical and } \\
\text { energetic concept } \\
{[16]}\end{array}$ \\
\hline $\begin{array}{l}\text { Principal } \\
\text { idea }\end{array}$ & $\begin{array}{l}\text { Effective separation of } \\
\text { the waste stream will } \\
\text { highly reduce its } \\
\text { amount coming to } \\
\text { disposal sites. }\end{array}$ & $\begin{array}{l}\text { Minimization of } \\
\text { wastes in the place of } \\
\text { MSW production or } \\
\text { control of its } \\
\text { production. }\end{array}$ & $\begin{array}{l}\text { Using flexible } \\
\text { manufacturing } \\
\text { system } \\
\text { guaranteeing } \\
\text { «non-waste } \\
\text { production». }\end{array}$ & $\begin{array}{l}\text { Consideration the } \\
\text { environmental } \\
\text { pollution factors } \\
\text { as a dispersed } \\
\text { system. }\end{array}$ \\
\hline Advantages & $\begin{array}{l}\text {-quite detailed } \\
\text { description of MSW } \\
\text { management } \\
\text { mechanism from } \\
\text { economical and } \\
\text { managerial positions; } \\
\text {-consideration of the } \\
\text { main aspects of MSW } \\
\text { problems in their } \\
\text { interrelation; } \\
\text {-stimulation of } \\
\text { waste production } \\
\text { decrease and others. }\end{array}$ & $\begin{array}{l}\text {-great decrease the } \\
\text { share of package in } \\
\text { gross mass of wastes } \\
\text { that consequently } \\
\text { leads to the decrease } \\
\text { of wastes amount } \\
\text { and processing the } \\
\text { most part of the waste. }\end{array}$ & $\begin{array}{l}\text {-formation of } 2 \\
\text { streams (for } \\
\text { easier } \\
\text { mechanical } \\
\text { separation); } \\
\text {-decrease the } \\
\text { number of } \\
\text { dump sites; } \\
\text {-using the } \\
\text { composting in } \\
\text { agriculture; } \\
\text {-land } \\
\text { reclamation, } \\
\text { employment of } \\
\text { population. }\end{array}$ & $\begin{array}{l}\text { - the choice of } \\
\text { techniques is } \\
\text { made taking into } \\
\text { account physical } \\
\text { process; } \\
\text {-design of } \\
\text { complex systems } \\
\text { for environmental } \\
\text { pollution } \\
\text { decrease, } \\
\text { including simpler } \\
\text { systems. }\end{array}$ \\
\hline $\begin{array}{l}\text { Disadvan- } \\
\text { tages }\end{array}$ & $\begin{array}{l}\text { - lack of attention to a } \\
\text { technological aspect; } \\
\text {-social and ecological } \\
\text { aspects are not taken } \\
\text { into account; } \\
\text {-commitment to } \\
\text { western specifications. }\end{array}$ & $\begin{array}{l}\text {-social and ecological } \\
\text { aspects are not taken } \\
\text { into account; } \\
\text {-«expensiveness» for } \\
\text { population. }\end{array}$ & $\begin{array}{l}\text {-return of } \\
\text { biological } \\
\text { wastes into the } \\
\text { soil; } \\
\text {-requirement of } \\
\text { certain territory } \\
\text { for composting; } \\
\text {-social aspect is } \\
\text { not taken into } \\
\text { account. }\end{array}$ & $\begin{array}{l}\text {-is not widely } \\
\text { realized } \\
\text { practically in the } \\
\text { field of MSW } \\
\text { handling }\end{array}$ \\
\hline
\end{tabular}

Each of these concepts has both advantages and disadvantages taking into account ecological, economical, social, technological, organizational and legal points of view.

The analysis of the above mentioned concepts from the ecological point of view that was carried out at the initial stage of our research showed their inadequate rationale and discovered the tendency of the concepts mainly to support economical and/or technological aspects. From the standpoint of the urban territory ecological safety the most interesting is an ecological aspect that should be taken into account at each stage of the MSW life cycle from production, collection and transport to preparation for using utility components and elimination or burial of unexploitable fractures because each step is followed by the environmental pollution. That is why a new approach is being developed which is called Physical and Energetic Description Concept of the Processes of Environmental Pollution and Restriction of Environmental Pollution with Municipal Solid Wastes [16].

Consequently, the strategies of MSW handling as a whole are directed to the sustainability concept, however they should be adapted to the conditions of a concrete country. In this regard, in spite of their identical direction, the choice criteria of this or that method of MSW utilization components is necessary with the purpose of urban territory ecological safety which would allow to evaluate the necessity of its appliance from ecological, economical and social points of view that is possible when detailed studying of 
MSW properties and is the purpose of the further research.

\section{Results}

The main idea of the concept under development is to consider a MSW handling system by studying physical pollution process and decreasing MSW environmental pollution using a theory of dispersed systems sustainability for description of properties and MSW behavior estimation [16].

The main research stages have been defined to achieve a concept goal (figure 1).

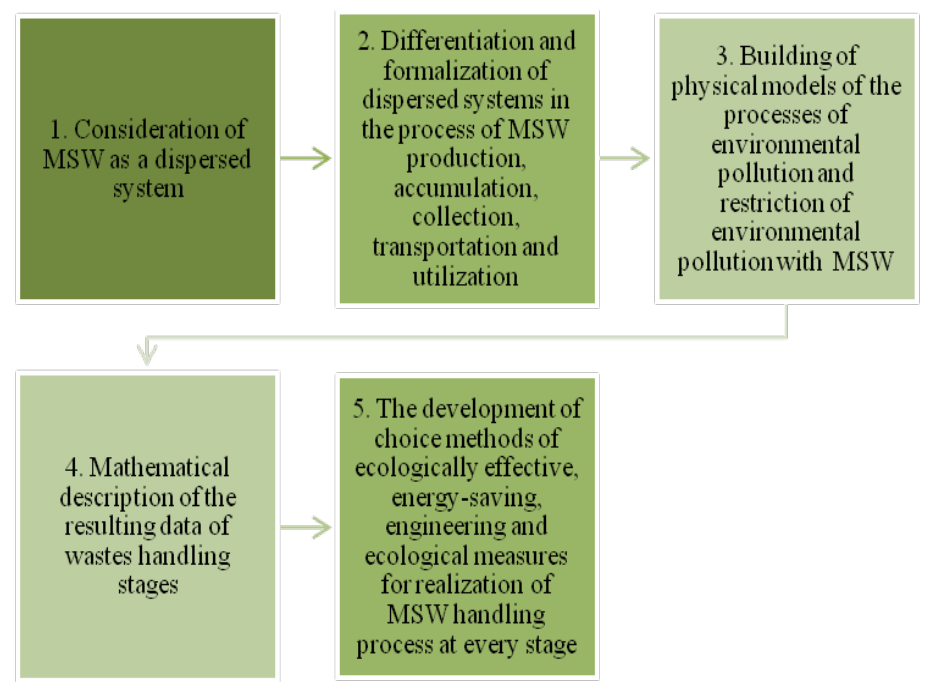

Fig. 1. The Main Stages of Research in the Form of Physical and Energetic Approach

According to the situation and requirements for further development of theoretical bases, techniques and ways of urban territories ecological safety when organizing the MSW handling system, the purpose of the first stage of the physical and energetic concept development is an analysis of MSW properties [17] on the basis of the dispersed system sustainability theory.

The processes of MSW production, emission and distribution are responsible for environmental pollution and in real conditions can occur either gradually or simultaneously in space and time $[1-3,18,19]$.

Existent approaches to studying of MSW properties practically don't consider the peculiarities of their behavior in the environment, don't enough open up interrelation between parameters of wastes and environment and don't in full take into consideration boundary conditions regarding this interrelation.

Recently, a number of researchers suggests to consider any contaminator as a dispersed system (V.I. Bespalov, P.A Kouzov, L.V.Senichev, V.A. Yargaeva and others). Such an approach realizes the theory of dispersed systems based on the classical rules of colloid and physical chemistry.

The principal classification features of dispersed systems applied to MSW are presented in table 2. 
Table 2. MSW Description According to Classification Types of Dispersed Systems

\begin{tabular}{|l|l|}
\hline \multicolumn{1}{|c|}{$\begin{array}{c}\text { Classification type of dispersed } \\
\text { system }\end{array}$} & $\begin{array}{l}\text { MSW characteristic } \\
\text { according to type }\end{array}$ \\
\hline Particle size, m & $0.05-0.35$ \\
\hline Dispersion degree & $\begin{array}{l}\text { Particulate, poly- } \\
\text { disperse }\end{array}$ \\
\hline $\begin{array}{l}\text { Interrelation type between disperse } \\
\text { phase and dispersion medium }\end{array}$ & lyophobe \\
\hline $\begin{array}{l}\text { Interrelation type between particles of } \\
\text { dispersed medium }\end{array}$ & free-disperse \\
\hline $\begin{array}{l}\text { Interrelation type between particles of } \\
\text { dispersion medium }\end{array}$ & free-disperse \\
\hline $\begin{array}{l}\text { Physical state of dispersed phase and } \\
\text { dispersion medium }\end{array}$ & Solid/gas \\
\hline
\end{tabular}

Thus, according to the dispersed system theory, MSW, in our opinion, is like a polydispersed system consisting of several solid dispersed phases (MSW single fractures) and gas dispersed medium (air space between MSW fractures) [20].

\section{Discussion}

The processes, identifying MSW properties and state, can not be considered separately from each other. The generality of these processes underlines a close interrelation between them. Herewith, one can say only about the influence domination of this or that process. This influence depends on a number of factors (MSW disperse phase (DP) and disperse medium (DM) properties, environment characteristics).

To learn the degree of impact of different process on MSW state it is necessary to study parameters identifying the behavior of these processes as well as parameters identifying DP and DM properties.

Thus, considering MSW as a disperse system it can be concluded that the description of MSW behavior can be built on the basis of the complex and gradual study of their state and the well-ordered investigation of DP and DM properties parameters. For this purpose, it is necessary to investigate DP and DM properties parameters in groups, the main classification sign of which is a MSW physical process and phenomena.

The parameters analysis about MSW state as a dispersed system allows to conclude that the following flow of parameters is reasonable for MSW behavior description (figure 2). 


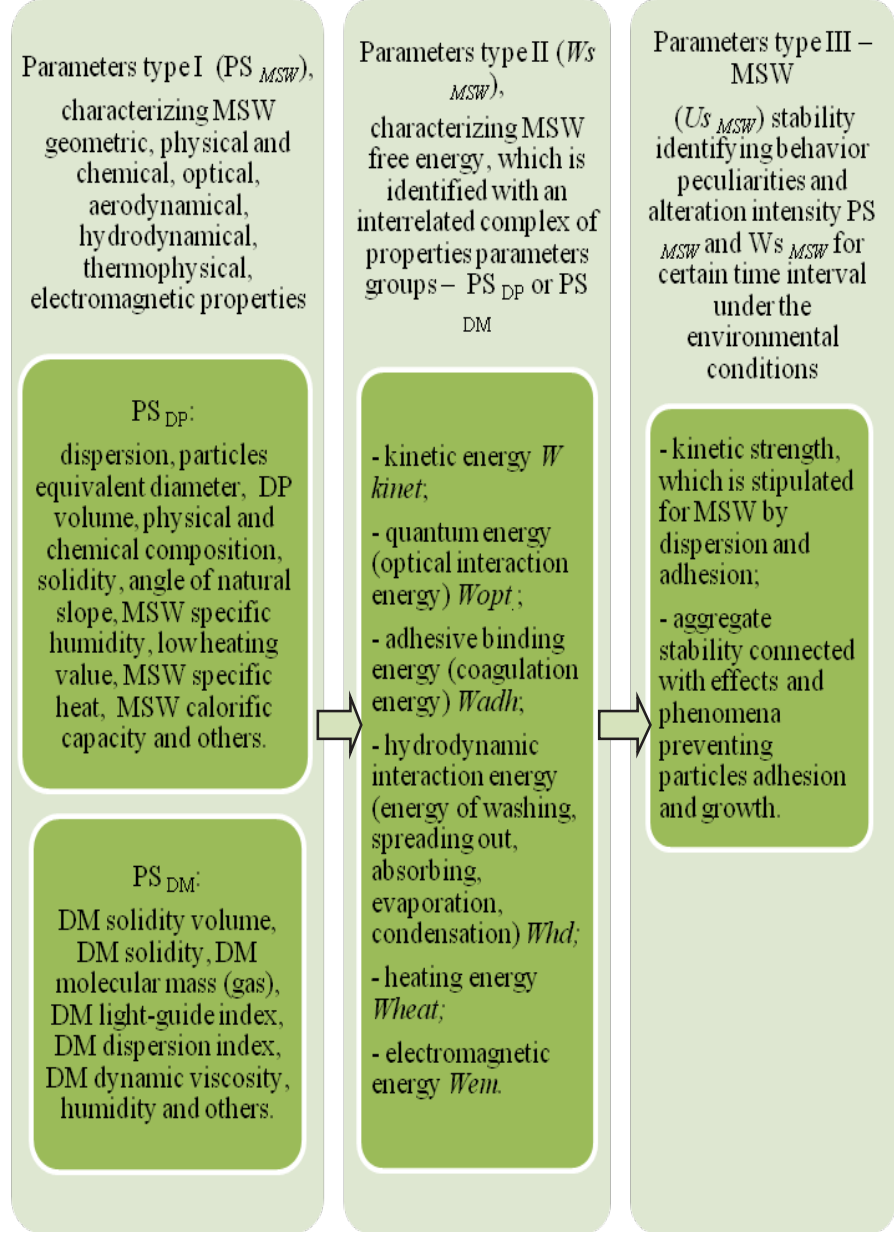

Fig. 2. Parameters, Identifying MSW Behavior in the Environment from the Dispersed Systems Theory Point of View

Result of the carried out analysis of parameters determining qualities of DP and DM could be expressed by aggregate of parameters determining qualities of MSW in general $\left(P S_{M S W}\right)$. In general obtained data could be represented as a functional dependence between groups of parameters of phase components of MSW:

$$
P S_{M S W}=f_{l}\left(P S_{D P,}, P S_{D M}\right)
$$

where $P S_{D P}$ - is the aggregate of parameters determining qualities of DP of MSW; $P S_{D M-}$ is the aggregate of parameters determining qualities of DM of MSW.

Such parameters generalization allows to complete every DP and DM parameters group with new characteristics in the process of the theory foundations development and to make a purposeful and gradual estimation of all sides of dynamics of MSW production, accumulation, distribution and decaying.

Free energy of disperse system functionally depends on DP and DM MSW specific energetic parameters that gives a possibility to redistribute some types of energy and to exhibit MSW behavior peculiarities.

Having a certain free energy store, MSW show the peculiarities of its behavior in the 
environment that finally have an effect on its stability: $W_{S}{ }_{M S W} \sim U_{M S W}$.

According to modern ideas, stability is a resulting characteristics, determining peculiarities of behavior of dispersion systems, i.e. parameters of their working life.

Stability is a characteristics of intensity of transformation of parameters of qualities and energy parameters of dispersion system for the certain time interval under the conditions of external influences.

Decrease of stability of dispersion systems is demonstrated either in strengthening of particles of DP (re-crystallization), or in adhesion and enlargement of these particles (creation of aggregates is happening).

In the process of MSW production, accumulation, distribution and utilization interrelated transits from one form of a disperse system into another one - «solid phase solid medium» (raw products, for example, foodstuffs etc.), «solid phase - gas medium» (MSW, for example, leftover food in a waste-bin). Herewith, the notions of raw product stability and MSW stability shouldn't be combined and it is supported by the following facts:

- while producing and accumulating of MSW the raw products resistance decreases (the disperse system is disintegrated in this case), but MSW resistance rises (energetic parameter points $W s$ increase).

- while distributing of MSW their resistance decreases (disperse system disintegrates because of solid phase gravity dropping), and raw products resistance (MSW settled fractions layer) grows.

Thus, considering MSW from the perspective of the dispersed system resilience theory, it can be revealed that the fundamental ways of MSW handling problems decisions are concluded in MSW destruction as a dispersed system by means of full loss of their stability.

\section{Conclusion}

Thus, at the first stage of our research, MSW properties parameters, MSW energetic parameters and their stability have been investigated and classified.

The given results will allow:

- to reveal principle characteristics of every wastes component, their properties, possibility of their further utilization;

- to identify their impacts on MSW components for decreasing their environmental effects;

- to control MSW behavior for decreasing their stability and restriction of environmental pollution as a result;

- to proceed the work - studying the processes of environmental pollution and restriction of environmental pollution with wastes and developing the physical model of relevant processes.

\section{References}

1. V.I. Bespalov, O.N. Paramonova, News RSSU, 14, 97-104 (2011)

2. V.I. Bespalov, O.N. Paramonova, Collection of Scientific Papers SWorld. Scientific research and its practical application. Current status and development trends 3- 9, 89 (2012)

3. V.I. Bespalov, O.N. Paramonova, Naukovedenie, 5(18) (2013) - URL: http://naukovedenie.ru/PDF/33trgsu513.pdf

4. E.E. Borovsky, Industrial and domestic waste: environmental problems (2007)

5. Ya. Weisman, V.N. Korotaev, N.N. Slyusarev, Waste Management. Collection, 
transport, compaction, sorting municipal solid waste (2012)

6. V.M. Garin, N.A. Klenow, A.G. Tail, Technology and utilization of waste (2005)

7. V.A. Grachev, A.T. Nikitin, S.A. Fomin, Handling the production and consumption of ecological safety system wastes (2008)

8. A.S. Grinin, V.N. Novikov, Industrial and domestic waste: storage, disposal, recycling (2002)

9. V.I. Smetanin, Environmental protection from waste production and consumption (2003)

10. L.Y. Shubov, A.K. Golubin, V.V. Devyatkin, Concept of solid waste management (2000)

11. L.Y. Shubov, M.E. Stavrovsky, A.V. Olejnik, Technology of municipal solid waste (2013)

12. O.M. Cherp, V.N. Vinichenko, Problem of municipal solid waste: an integrated approach (1996)

13. R. Murray, Target - Zero Waste (2004)

14. Forbes R. McDougall, Peter R. White, Marina Franke, Peter Hindle, Integrated Solid Waste Management: A Life Cycle Inventory, (2008)

15. Europeans practice of waste management: problems, solutions and prospects (2005)

16. V.I. Bespalov, O.N. Paramonova, European Applied Sciences is an international, 1, 202-204 (2013)

17. URL: http://portaleco.ru/ekologija-goroda/sostav-svojstva-i-obem-tverdyh-bytovyhothodov.html

18. V.M. Shmandy, Management of technogenic safety urbosistemy at Obration stage and waste into the environment, 2, 152 (2001)

19. V.M. Shmandy, E.V. Harlamova, T.E. Rigas, Ecological Bulletin of the North Caucasus, 10, 53 - 63 (2014)

20. O. N. Paramonova, Engineering Don Gazette, 3 (2013) 